\title{
Modulation of gap junction mediated intercellular communication in TM3 Leydig cells
}

\author{
R C S Goldenberg ${ }^{1}$, F S A Fortes ${ }^{1}$, J M Cristancho ${ }^{1,3}$, \\ M M Morales ${ }^{1}$, C R Franci ${ }^{2}$, W A Varanda ${ }^{2}$ \\ and A C Campos de Carvalho ${ }^{1}$ \\ ${ }^{1}$ Institute of Biophysics Carlos Chagas Filho, UFRJ, Brazil \\ ${ }^{2}$ Department of Physiology, Faculty of Medicine of Ribeirão Preto, USP, Av. Bandeirantes, 3900 14049-900 Ribeirão Preto, Brazil \\ ${ }^{3}$ Surcolombian University, Neiva, Colombia \\ (Requests for offprints should be addressed to A C C de Carvalho, Instituto de Biofísica Carlos Chagas Filho, Universidade Federal do Rio de Janeiro, \\ Av. Brigadeiro Trompowsky s/n, Cidade Universitária, Ilha do Fundão, Rio de Janeiro RJ 21941-900, Brasil; Email: acarlos@biof.ufrj.br)
}

\begin{abstract}
Long-term modulation of intercellular communication via gap junctions was investigated in TM3 Leydig cells, under low and high confluence states, and upon treatment of the cells for different times with activators of protein kinase $\mathrm{A}$ (PKA) and protein kinase $\mathrm{C}$ (PKC). Cells in low confluence were readily coupled, as determined by transfer of the dye Lucifer Yellow; on reaching confluence, the cells uncoupled. Western blots and RT-PCR revealed that connexin 43 (Cx43) was abundantly expressed in TM3 Leydig cells and its expression was decreased after the cells achieved confluence. Stimulation of PKA or PKC induced a decrease in cell-cell communication. Staurosporin, an inhibitor of protein kinases, increased coupling and was able to prevent and reverse the uncoupling actions of dibutyryl cAMP and 12-O-tetradecanoyl-phorbol-13-
\end{abstract}

acetate (TPA). Under modulation by confluence, $\mathrm{Cx} 43$ was localized to the appositional membranes when cells were coupled and was mainly in the cytoplasm when they were uncoupled. In addition, cAMP and TPA reduced the surface membrane labeling for $\mathrm{Cx} 43$, whereas staurosporin increased it. These data show a strong correlation between functional coupling and the membrane distribution of Cx43, implying that this connexin has an important role in intercellular communication between TM3 cells. Furthermore, increased testosterone secretion in response to luteinizing hormone was accompanied by a decrease in intercellular communication, suggesting that gap junction mediated coupling may be a modulator of hormone secretion in TM3 cells.

Journal of Endocrinology (2003) 177, 327-335

\section{Introduction}

Gap junctions are plasma membrane specializations responsible for the transfer of small molecules (up to $\sim 1 \mathrm{kDa}$ ) and ions between adjoining cells (Bennett et al. 1991). Gap junction mediated intercellular communication has been implicated in fundamental cellular processes such as embryonic development, cell differentiation, proliferation and growth control. The proteins forming gap junctions, named connexins, are phosphoproteins (with the exception of connexin 26 (Cx26)) that can be phosphorylated by protein kinases activated by neurotransmitters, growth factors, hormones, oncogenes and exogenous chemicals. In particular, activation of protein kinases A and $\mathrm{C}$ is known to modulate junctional communication between cells. PKC has been shown to phosphorylate Cx43 in serine and threonine residues of the carboxyl tail of the protein (Moreno et al. 1994, Oh et al. 1991), but to date the phosphorylation of Cx43 by PKA has not been unequivocally shown. Nevertheless, 12-O-tetradecanoylphorbol-13-acetate (TPA) and cAMP have been found to induce a variety of effects in cells expressing Cx43, leading both to inhibition and to enhancement of gap junction communication, depending on cell type and developmental stage (Oh et al. 1991, Risley et al. 1992, Xie \& Hu 1992, Hünster \& Weingant 1993, Lampe 1994).

In the testis, cellular interactions are essential for adequate functioning of many different cell types (Skinner 1982) and, to date, 11 types of connexin have been identified in its constituent cells (Kadle et al. 1991, Haefliger et al. 1992, Risley et al. 1992, Risley 2000). Freshly dissociated Leydig cells show both electrical and metabolic coupling, and $\mathrm{Cx} 43$ has been reported as the main functional component of their gap junctions (PérezArmendariz et al. 1994, Varanda \& Campos de Carvalho 1994). Although electrical characteristics of the gap junction in these cells have been well characterized, modulation processes have not yet been extensively 
studied. Given that gap junction communication has been shown to modulate secretion in endocrine and exocrine organs (Rüegg \& Burgess 1989, Granot \& Dekel 1994, You et al. 2000), it is important to study the regulation of junctional communication in TM3 Leydig cells. The main purpose of the present study was to examine the extent to which coupling between these cells can be influenced by PKA and PKC, and to correlate this modulation of coupling to the expression of $\mathrm{Cx} 43$ and the secretion of testosterone.

\section{Materials and Methods}

\section{Cell culture}

TM3 Leydig cells, a non-tumorogenic cell line derived from mouse testis, were obtained from the American Type Culture Collection. We decided to use this cell line in our studies because they respond to luteinizing hormone (LH) by increasing testosterone production and secretion, through mechanisms similar to those encountered in freshly isolated cells. The cells were grown in a mixture of Ham's F-12 medium plus Dulbecco's Modified Eagle Medium (1:1 v:v), supplemented with $5 \mathrm{mM} \mathrm{NaHCO}$, $15 \mathrm{mM} \quad N$-[2-hydroxyethyl] piperazine- $N^{\prime}$-[2-ethane sulfonic acid], $7 \cdot 5-10 \%$ fetal bovine serum and $1 \%$ penicillin/streptomycin, $\mathrm{pH} 7 \cdot 4$. Serum concentration $(7.5$ or $10 \%)$ did not affect cell properties. Cells were plated at either low or high density, depending on the type of experiment intended, for at least $12 \mathrm{~h}$ before the experiment, and then treated with a specific drug for times ranging from $15 \mathrm{~min}$ to $12 \mathrm{~h}$. For subconfluent cultures, the cells were plated at approximately $200 \mathrm{cells} / \mathrm{mm}^{2}$. For confluent cultures, the cells were plated at $400 \mathrm{cells} / \mathrm{mm}^{2}$. At the time of the experiments, the low-density cultures had 320 cells $/ \mathrm{mm}^{2}$ and high-density cultures had 650 cells $/ \mathrm{mm}^{2}$. The cells were always cultured in the presence of fetal bovine serum and kept in an atmosphere of 5\% $\mathrm{CO}_{2}$ and $95 \% \mathrm{O}_{2}$ at $37{ }^{\circ} \mathrm{C}$ in an incubator (Forma Scientific).

\section{Dye transfer}

TM3 cells in low- or high-confluence cultures were plated in plastic dishes and injected with Lucifer Yellow $\mathrm{CH}(5 \%$ in $150 \mathrm{mM} \mathrm{LiCl}$ without $\mathrm{pH}$ adjustment), with the aid of glass microelectrodes (resistance between 40 and $70 \mathrm{M} \Omega$ ) by application of short hyperpolarizing current pulses (0.1 nA, $100 \mathrm{~ms})$, using a WPI amplifier model 7060. Dye transfer was observed in a Nikon Diaphot inverted microscope, equipped with xenon arc illumination, and photographs were taken using Kodak TMAX400 film, 2 min after injection of dye into one cell (Srivinas et al. 1999). For measurement of modulation of coupling by pharmacological agents, a minimum of 90 cells were injected for every time point in each of at least three independent experiments; values were plotted as a function of time after drug application. The percent of coupled cells was evaluated as the number of injections that resulted in the transfer of Lucifer Yellow to neighboring cell(s), in relation to the total number of injections in a given assay. Results are presented as means \pm S.E.M.

\section{Immunofluorescence and Western blots}

Cultured TM3 cells were plated in high or low confluence on $25 \mathrm{~cm}^{2}$ plastic culture flasks or glass coverslips, previously treated with poly-L-lysine, for Western blot and immunofluorescence respectively. Cells were kept in culture for at least $12 \mathrm{~h}$ before experimental maneuvers. For western blots, the TM3 cells were treated with dibutyryl (db)-cAMP or TPA for $12 \mathrm{~h}$. Staurosporin was used in TM3 cells after the $12 \mathrm{~h}$ treatment with PKA and PKC activators, and cells were incubated for $1 \mathrm{~h}$ with staurosporin. Homogenates from sister cultures (control and treated) were obtained by scraping $25 \mathrm{~cm}^{2}$ flasks in $1 \mathrm{mM} \mathrm{NaHCO} 3$ (pH 8.3) containing $1 \mathrm{mM}$ of the protease inhibitor phenylmethylsulfonyl fluoride (PMSF), and were centrifuged at 10000 r.p.m. for $10 \mathrm{~min}$. Total protein content was determined by the Bradford method (Bradford 1976) and $100 \mu \mathrm{g}$ samples were loaded in each lane of a $10 \%$ SDS-PAGE system. Protein was then transferred to nitrocellulose and the membrane was incubated with polyclonal antibody to residues 346-360 of the Cx43 sequence (kindly provided by Dr E L Hertzberg, Albert Einstein College of Medicine, New York, USA), as previously described (Varanda \& Campos de Carvalho 1994). Heart homogenate was used as positive control and densitometry was performed using the gel analysis software Sigma Gel (v1·1, Jandel Scientific, Chicago, IL, USA). Results are presented as means \pm S.E.M.

For immunofluorescence, the cells were treated with db-cAMP, TPA or staurosporin for the same time intervals described above and then fixed in ethanol (70\%) at $-20{ }^{\circ} \mathrm{C}$ for $20 \mathrm{~min}$. $\mathrm{Cx} 43$ was detected as described previously for other cell types (Dermietzel et al. 1991). In short, cells were incubated, for $30 \mathrm{~min}$ at room temperature, with $0 \cdot 1 \%$ IgG-free bovine serum albumin (BSA) to reduce non-specific binding. This was followed by incubation with the polyclonal antibody for $\mathrm{Cx} 43$, described above, diluted $1 / 500$, for $1 \mathrm{~h}$ at room temperature. Then the cells were washed four times, for $10 \mathrm{~min}$ each time, with phosphate-buffered saline (PBS) and incubated with the secondary antibody (goat anti-rabbit IgG conjugated with fluorescein isothiocyanate diluted $1 / 150)$, for $1 \mathrm{~h}$ at room temperature. The coverslips were then washed with PBS four times, for $10 \mathrm{~min}$ each time, and mounted with $10 \mu \mathrm{l}$ of a solution containing $P$-phenylenediamine+ glycerol + PBS in the proportions 29:9:1. Fluorescence was observed on a Zeiss Axiovert 100 microscope. Because of the repeated washes and poor adherence of TM3 
cells to the coverslips, it was common to lose cells during processing for immunofluorescence.

\section{Radioimmunoassay}

Leydig cells were cultured in $75 \mathrm{~cm}^{2}$ flasks and subjected to treatment with LH (LH-RP3 No. AFP7187B; National Institute of Diabetes, Digestive and Kidney Diseases, USA) for the indicated times. Testosterone concentration was assayed in the incubation media by radioimmunoassay. Cells in five different incubation bottles were treated with either 1 or $10 \mathrm{ng} / \mathrm{ml} \mathrm{LH}$. The results are normalized for $10^{6}$ cells (number of cells determined by counting in Neubauer chamber) and the initial value (zero time) was taken as the concentration of testosterone detected in the incubation medium (DMEM+10\% FCS) without cells. ${ }^{3} \mathrm{H}$-Testosterone was obtained from NEN Life Science Products and the specific antibody was a generous gift from Dr José Antunes Rodrigues (Department of Physiology, Faculty of Medicine of Ribeirão Preto, University of São Paulo, Brazil). The lower limit of detection of the assay was $0.3 \mathrm{ng} / \mathrm{ml}$ sample and the intra-assay coefficient of variation was $5 \cdot 4 \%$.

\section{Isolation of total RNA}

Total RNA from all subconfluent or confluent cells and rat heart tissue was extracted by Trizol reagent (Gibco brl, Grand Island, NY, USA). RNase-free DNase I (1 U/ $\mu \mathrm{l})$ was used to treat the isolated RNA for $1 \mathrm{~h}$, to eliminate contamination with genomic DNA. The treatment was terminated by extraction with phenol-chloroform-isoamyl alcohol (PCI) in the proportions 25:24:1 (vol/vol) and precipitation with ethanol.

\section{Reverse transcriptase-polymerase chain reaction}

In order to prepare first-strand DNA, total RNA isolated from TM3 Leydig cells $(n=3-4)$ and rat heart cells was reverse-transcribed with SuperScript (Gibco brl) at $37^{\circ} \mathrm{C}$ for $60 \mathrm{~min}$, extracted with PCI and precipitated with ethanol. The cDNA synthesis was primed with oligo-dT primer. A PCR technique was used to amplify the synthesized cDNA. The following solution was used: $0.2 \mu \mathrm{mol} / 1$ primers, $0.2 \mathrm{mmol} / 1$ each dNTP, $50 \mathrm{mmol} / 1$ $\mathrm{KCl}, 10 \mathrm{mmol} / \mathrm{l}$ Tris $\mathrm{HCl}(\mathrm{pH} 8.3)$ and $1.5 \mathrm{mmol} / 1$ $\mathrm{MgCl}_{2}$ plus $2 \cdot 5 \mathrm{U}$ Amplitaq (Perkin Elmer, New Jersey, NJ, USA). The primers synthesized for $\mathrm{Cx} 43$ (sense: 5'-ATGAGCAGTCTGCCTTTCGT-3'; antisense: 5'CACCACCAGCATGAAGATGA-3') correspond to nucleotides 346-366 and 2076-2093 respectively of the rat $\mathrm{Cx} 43$ sequence (GeneBank accession number: XM 027460) and are predicted to amplify a $459 \mathrm{bp}$ PCR product. PCR was performed with 34 cycles of denaturation $\left(94^{\circ} \mathrm{C}, 1 \mathrm{~min}\right)$, annealing $\left(55^{\circ} \mathrm{C}, 1 \mathrm{~min}\right)$ and extension $\left(72^{\circ} \mathrm{C}, 1 \mathrm{~min}\right)$. Rat glyceraldehyde-3-phosphate dehydrogenase (GAPDH) primers predicted to amplify a $221 \mathrm{bp}$ PCR product (sense: 5'-GTCTTCACCACCAT GGAG-3'; antisense: 5'-CGATGCCAAAGTTGTCA TG-3') corresponding respectively to nucleotides 326-343 and $518-536$ of the rat GAPDH gene were added into the same RT-PCR reaction tubes and their products were used as internal controls (GeneBank accession number: M17701). PCR products were size-fractionated by agarose gel electrophoresis. The expected $\mathrm{Cx} 43$ and GAPDH bands from the same sample were submitted to a densitometry analysis using the gel analysis software Sigma Gel (v1·1, Jandel Scientific) and normalized by dividing the $\mathrm{Cx} 43$ values by the corresponding GAPDH values.

The semi-quantitative method of RT-PCR used for studies of expression of Cx43 mRNA in TM3 Leydig cells was validated in preliminary experiments. Firstly, the optimal PCR conditions that yielded a single band on agarose gel eletrophoresis were determined for $\mathrm{C} x 43$ and GAPDH genes in the same reaction tube. Secondly, to determine whether the method was semi-quantitative, serial quantities of total RNA $(62 \cdot 5,125,250,500,1000$ and $2000 \mathrm{ng}$ ) extracted from TM3 cells were used for RT-PCR amplification for Cx43 and GAPDH genes in the same reaction tube. Thirdly, experiments were performed to determine the optimal number of PCR cycles that yielded PCR products in the linear phase of amplification of both genes in the same reaction. Finally, to ensure that the reactions were consistent, PCR reactions were performed at least twice. Only one of these reactions was included for final densitometry analysis, and the selection was arbitrary. For the semi-quantitative PCR comparing the confluent and subconfluent cells and the drug treatments, the optimal total amount of RNA was $500 \mathrm{ng}$ and the optimal number of PCR cycles was 34 . All reactions included a negative control $\mathrm{RT}(-)$. The identity of the amplification was confirmed by determination of the molecular size on agarose gel electrophoresis with a 100 bp DNA molecular marker (Gibco brl). Results are presented as means \pm S.E.M.

\section{Statistical analysis}

One-way analysis of variance followed by the NewmanKeuls multiple comparison test was used for data presented in Figs 2, 3 and 6. For data given in Fig. 1 we used the $\chi^{2}$ test, and for those in Figs 4, 5, 8 and 9 we performed Student's non-paired $t$-test. In all cases, statistical significance was considered to be present at $P<0 \cdot 05$.

\section{Results}

When examined at high density in confluent cultures, TM3 Leydig cells showed a poor degree of dye coupling (Fig. 1A, B) demonstrated by the low proportion of injections that resulted in the spread of Lucifer Yellow 

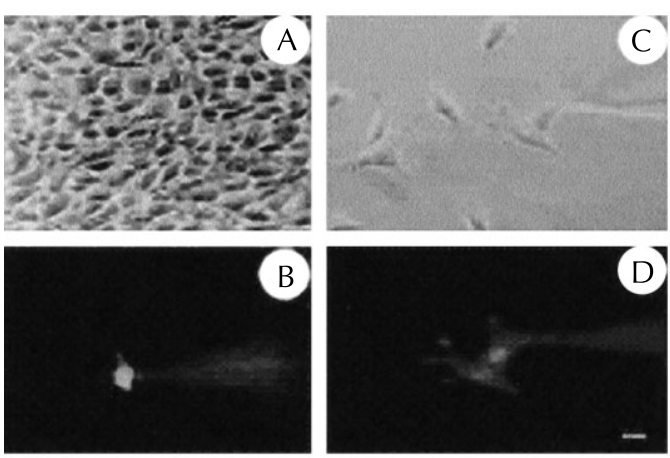

Figure 1 Gap junction coupling between TM3 Leydig cells. (A) Phase and (B) fluorescence pictures of cells cultured under high confluence; (C) phase and (D) fluorescence pictures of cells forming pairs in a low-confluence culture. In (B) and (D) Lucifer Yellow was injected in one cell and pictures taken 2 min later. (E) Histogram of the percentage of coupled cells in each condition. Low, low-confluence cultures; High, high-confluence cultures; Pairs, cells in low confluence forming pairs; n, number of cells that were injected with Lucifer Yellow in each condition. Calibration bar in (D) represents $20 \mu \mathrm{m}$. between the cells $(3 \%(n=108)$, histogram in Fig. 1$)$. In contrast, when cultured at low density as subconfluent cultures, the cells showed a high degree of coupling, with $80 \%$ of the injected cells $(n=20)$ showing transfer of the dye. This number is very similar to that observed in cell pairs (Fig. 1C, D) in which $87 \%$ of the pairs were coupled $(n=131$, histogram in Fig. 1), and is in agreement with previous reports based on electrophysiological measurements (Pérez-Armendariz et al. 1994, Varanda \& Campos de Carvalho 1994, Cristancho et al. 2000).

Western blots revealed the presence of Cx43 in TM3 cells. Figure 2 illustrates an experiment in which $\mathrm{Cx} 43$ was detected in subconfluent and confluent sister cultures. Densitometry shows that the labeling was more intense for subconfluent (lane 1) than for confluent (lane 2) cultures, indicating that the expression of this protein is modulated by contact between the cells.

The results of semi-quantitative RT-PCR using Cx43specific oligonucleotides and RNA extracted from Leydig cells in confluent and subconfluent cultures are shown in Fig. 3. Expression of $\mathrm{Cx} 43 \mathrm{mRNA}$ was reduced in confluent cultures (to $47 \cdot 5 \%$ of subconfluent culture values, $P<0 \cdot 05)$, in agreement with the diminished expression of protein.

It is widely accepted that db-cAMP and TPA activate PKA and PKC respectively (Berridge 1984). PKA activation generally leads to increased intercellular communication, but PKC activation usually has the opposite effect. Figure 4A shows the effect of PKA activation on gap junction intercellular communication 1,6 and $12 \mathrm{~h}$ after a single addition of db-cAMP $(0.5 \mathrm{mM})$ to the culture medium. Figure 4B illustrates similar experiments using TPA (50 nM) to activate PKC. Both cAMP and TPA greatly reduced gap junction intercellular communication in subconfluent TM3 cell cultures. A significant reduction was already apparent in the first $1 \mathrm{~h}$ after addition of the drugs to the medium ( $>80 \%$ of the cells uncoupled), and this was maintained after $12 \mathrm{~h}$ of a single drug application.

Staurosporin, an inhibitor of protein kinases, is able to couple TM3 cells in confluent cultures and to reverse the uncoupling effects of both TPA and c-AMP in subconfluent cultures. Figure 5 illustrates a typical experiment in which cells in a subconfluent culture were injected with

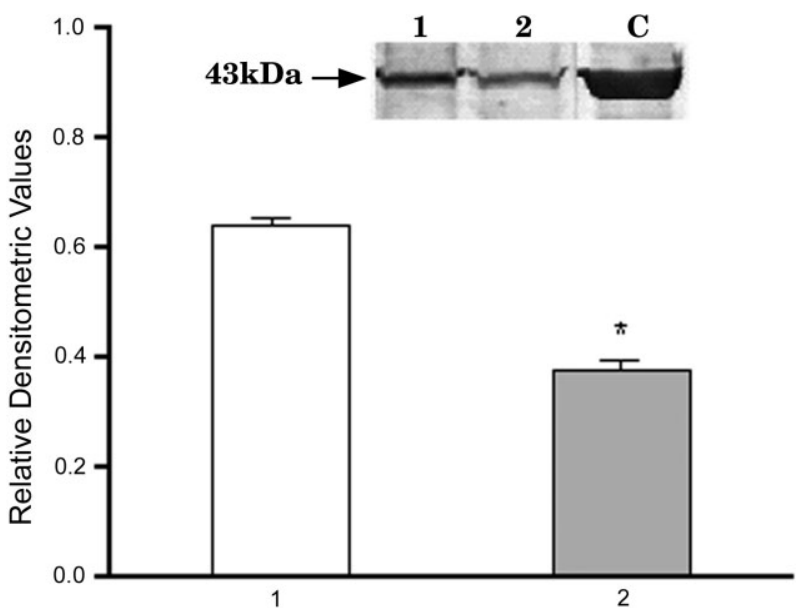

Figure 2 Western blot for Cx43. Lanes 1 and 2: homogenates of TM3 Leydig cells cultured under low and high confluence, respectively. Lane C: a rat heart homogenate used as positive control for Cx43. Each lane of the gel was loaded with $100 \mu \mathrm{g}$ total protein before transfer to nitrocellulose. The band for cells in low confluence was more intensely marked than that for high-confluence cells. As the amount of protein loaded in the gel was the same, this difference can be used as a semi-quantitative estimate of $\mathrm{Cx} 43$ expression. The histogram represents the mean \pm S.E.M. $(n=3)$ of the relative densitometry values for $\mathrm{C} \times 43$ labeling, taking the rat heart homogenate as control. *Protein expression in confluent cultures was significantly different from that in subconfluent ones $(P<0 \cdot 05)$. 


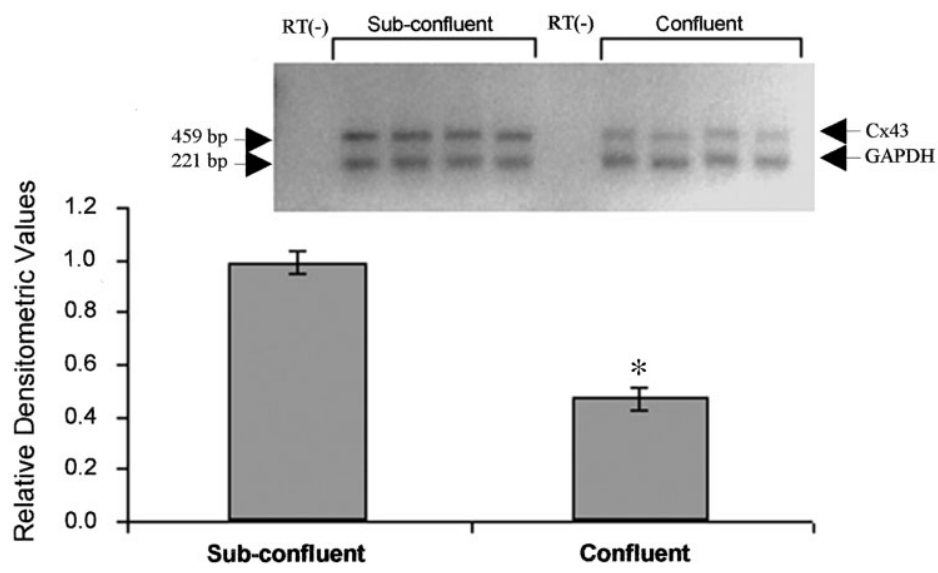

Figure 3 Relative expression of $\mathrm{Cx} 43$ in total RNA isolated from subconfluent and confluent TM3 Leydig cells: results obtained by amplifying Cx43 and GAPDH RT-PCR products. The histogram represents the mean \pm S.E.M. for the ratio between the $\mathrm{Cx} 43$ and GAPDH bands $(n=4)$. The insert shows the agarose gel of a semi-quantitative RT-PCR experiment. RT(-), negative control, performed with 500 ng total RNA derived from subconfluent cells in the absence of reverse transcriptase. *Expression of mRNA in confluent cultures was significantly different from that in subconfluent cultures $(P<0 \cdot 05)$.

Lucifer Yellow, db-cAMP $(500 \mu \mathrm{M})$ was added for $1 \mathrm{~h}$ and dye coupling was again measured, and then $1 \mathrm{mM}$ staurosporin was added, in the presence of db-cAMP, for $30 \mathrm{~min}$ and coupling was assayed once more. The histogram shows that staurosporin restored gap junction intercellular communication to the control condition even in the presence of $\mathrm{db}$-cAMP. Similar results were obtained when cells were treated first with TPA and then with staurosporin (not shown).
Interestingly, total expression of the $\mathrm{Cx} 43$ protein in TM3 Leydig cells treated with cAMP, TPA and staurosporin was not altered in relation to control (Fig. 6A). Accordingly, semi-quantitative RT-PCR using total RNA from the same treated cells showed that $\mathrm{Cx} 43$ mRNA was not altered in relation to that in control cultures (Fig. 6B).

Indirect immunofluorescence was used to evaluate whether the cellular localization of $\mathrm{Cx} 43$ was directly
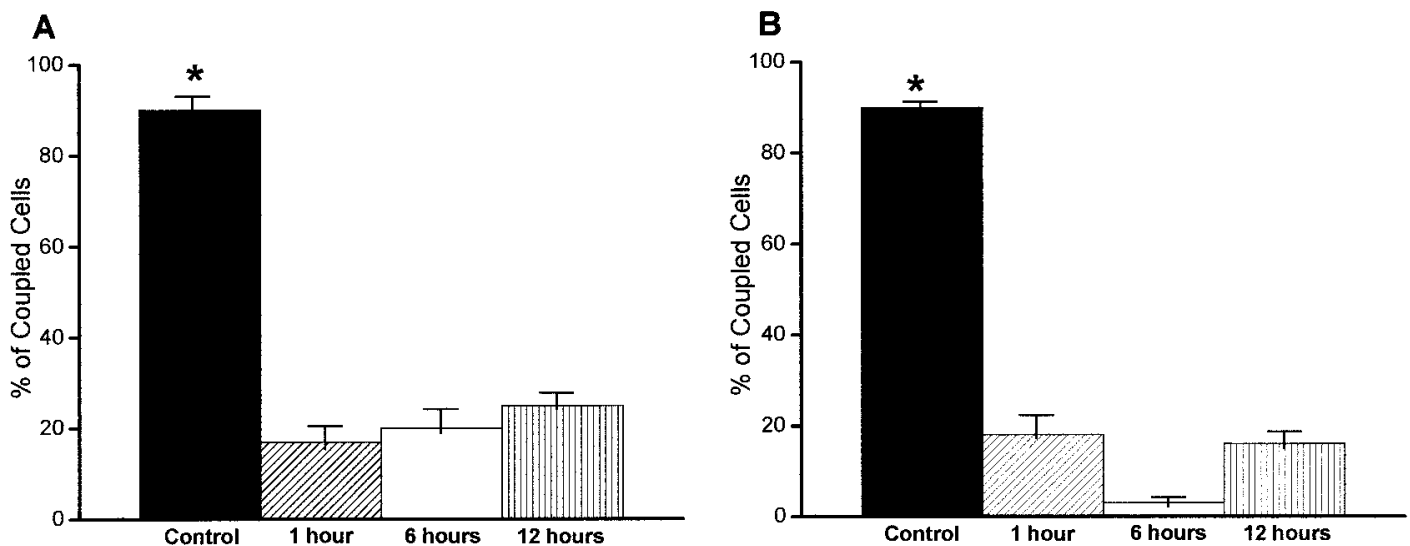

Figure 4 Junctional coupling in TM3 Leydig cells was decreased by cAMP (A) or TPA (B). The drugs were added to subconfluent cultures at a concentration of $500 \mu \mathrm{M}$ for cAMP or $50 \mathrm{nM}$ for TPA, for 1, 6 and $12 \mathrm{~h}$. Control, no drug added. The degree of coupling was assessed by injecting Lucifer Yellow in one cell of a group and counting the number of cells labeled after 2 min. A total of 720 cells was injected in three different culture dishes for each group (control, $1 \mathrm{~h}, 6 \mathrm{~h}$ and $12 \mathrm{~h}$ ). For each experiment, the percentage of coupled cells (number of injected cells that passed dye to neighbors/total number of injected cells) was determined and means \pm S.D. were plotted for each experimental condition. *Coupling in the control was significantly greater than that in any of the treated cultures $(P<0 \cdot 05)$. 


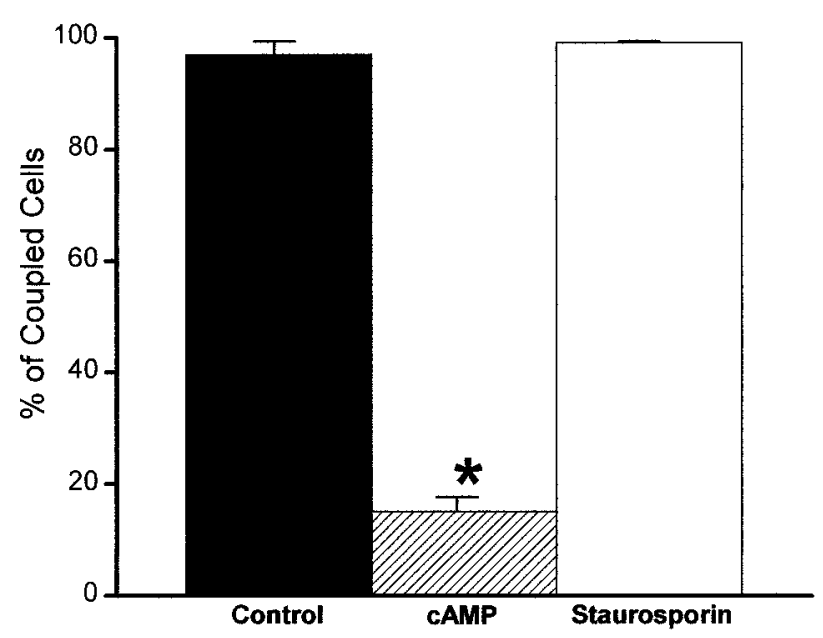

Figure 5 Staurosporin reversed the uncoupling effect of cAMP. At least 30 cells were injected with Lucifer Yellow in each of these subconfluent-culture dishes. The percentage of coupled cells in each dish was determined and means \pm S.D. were plotted (number of cells injected in each condition was 90). Control coupling was determined $12 \mathrm{~h}$ after plating (black bar); cAMP $(500 \mu \mathrm{M})$ was applied to the same cultures for $1 \mathrm{~h}$ and coupling was again determined (cross-hatched bar). Staurosporin $(1 \mathrm{mM})$ was then added in the presence of CAMP, restoring the degree of coupling to control values (open bar). *Coupling during cAMP treatment was significantly lower than that in the two other groups $(P<0 \cdot 05)$.

related to coupling in cells at low and high confluence. In low-confluence cultures and in pairs of TM3 Leydig cells, immunoreactivity for $\mathrm{Cx} 43$ was detected at appositional membranes, in addition to diffusely in the cytoplasm (Fig. 7A). In high-confluence cultures, TM3 Leydig cell immunoreactivity was detected mainly as points dispersed in the cytosol, with no detectable labeling in appositional membrane regions (not shown). In agreement with the findings of the dye-coupling experiments, when subconfluent cultures or cell pairs were treated with $500 \mu \mathrm{M}$ db-cAMP (Fig. 7B) or $50 \mathrm{nM}$ TPA (Fig. 7C) for $1 \mathrm{~h}$, they showed labeling over the cytosol and the perinuclear region, with disappearance of the appositional labeling (compare Figs 7A, 7B and 7C). In contrast, confluent cells treated with $1 \mathrm{mM}$ staurosporin for $1 \mathrm{~h}$ showed intense reactivity at the appositional membranes (Fig. 7D). Incubation with secondary antibody alone did not label the cells (not shown).

To investigate the effects of a physiological modulator of Leydig cells, we exposed TM3 subconfluent cultures to $\mathrm{LH}$ and measured hormone secretion and gap junction intercellular communication in the cultures. When testosterone secretion by the TM3 cells in subconfluent cultures was determined during a $12 \mathrm{~h}$ period, control values were within the ranges reported in the literature (PérezArmendariz et al. 1996). Upon exposure of the cells to LH (1 or $10 \mathrm{ng} / \mathrm{ml}$ ), testosterone secretion increased during the first hour and then was maintained at high levels during the $12 \mathrm{~h}$ period (Fig. 8). Figure 9 shows that, $15 \mathrm{~min}$ and $1 \mathrm{~h}$ after application to TM3 Leydig cells, LH in concentrations of 1 and $10 \mathrm{ng} / \mathrm{ml}$ significantly reduced gap junction intercellular communication and that, $3 \mathrm{~h}$ after exposure of the cells to LH, coupling was totally abolished. These results were to be expected, because LH acts by increasing adenyl cyclase activity in these cells, resulting in activation of PKA.

\section{Discussion}

In this study we have shown that TM3 Leydig cells are coupled through intercellular gap junctions in a manner similar to that described for freshly dissociated Leydig cells from mouse testis (Pérez-Armendariz et al. 1994, 1996, Varanda \& Campos de Carvalho 1994). We have also shown that the junctional communication between TM3 cells is modulated by cell density, as coupling in cells under high confluence was lower than that observed under low confluence or in cell pairs.

Cx43 has an important role in gap junction communication in TM3 Leydig cells, based on the correlation between modulation of cell-cell coupling and the expression of $\mathrm{Cx} 43$ at appositional membranes shown in this study. Previous experiments in which we showed that junctional conductance properties in TM3 cells were similar to those obtained in communication-deficient cell lines transfected with Cx43 cDNA reinforce this idea. To date, 11 different connexins have been reported to be present in the testis, communicating between the different cell types that constitute this organ (Kadle et al. 1991, Haefliger et al. 1992, Risley et al. 1992, Risley 2000). Preliminary experiments using RT-PCR in TM3 Leydig cells have identified six connexin transcripts, of which connexins 31, 37, 40, 43, 45 and 50 have been described in testis (Risley 2000). Whether or not all these connexins contribute to functional coupling between TM3 cells remains to be investigated.

Our experiments show that, in TM3 Leydig cells, $\mathrm{db}$-cAMP and TPA drastically reduce junctional coupling $1 \mathrm{~h}$ after application. A rapid decrease (in minutes) in electrical coupling has been reported (Cristancho et al. 2000) after activation of PKA and PKC, indicating that these protein kinases act to reduce intercellular communication by both short- and long-term mechanisms in TM3 cells. These findings are consistent with the hypothesis that their activation may induce effects directly on the channel - with respect to the fast reduction in junctional conductance - and may also interfere with the assembly, degradation, or both, of channel protein. In agreement with that, a $12 \mathrm{~h}$ exposure to cAMP or TPA induced disappearance of $\mathrm{Cx} 43$ membrane reactivity, restricting it to the cytoplasm of cells in subconfluent cultures, whereas total $\mathrm{Cx} 43$ protein concentrations and message levels were unaltered by these treatments. 
A

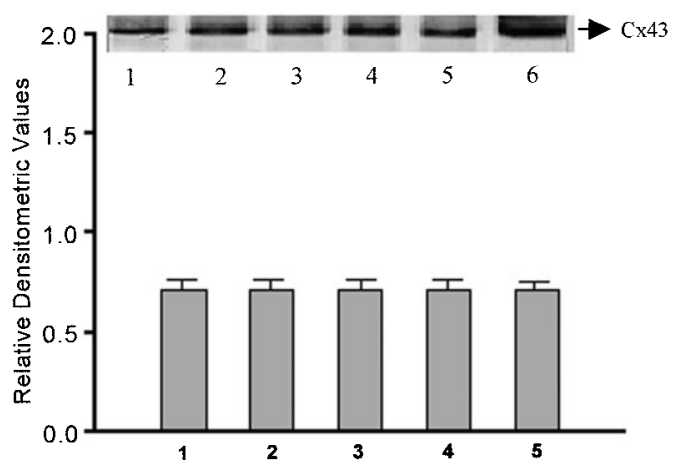

B

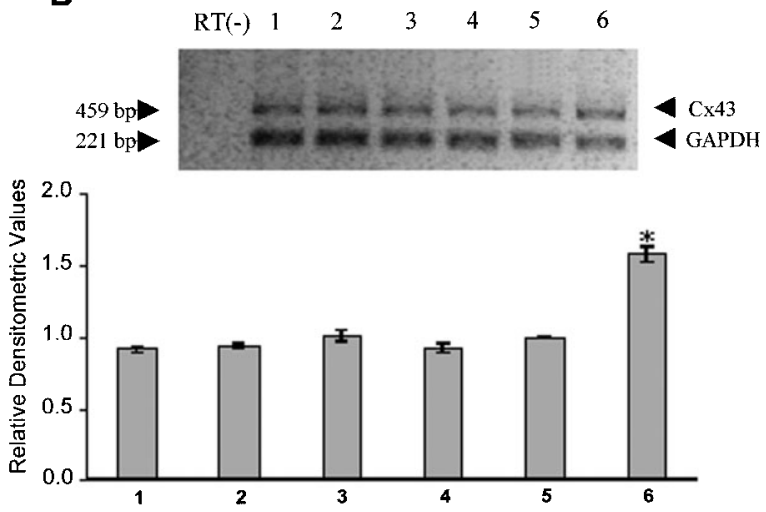

Figure 6 cAMP, TPA and staurosporin did not affect the expression of Cx43 protein (A) or mRNA (B). (A and B) Lanes 1-4: homogenates of TM3 subconfluent Leydig cell cultures treated with TPA+staurosporin, CAMP+staurosporin, TPA, and cAMP respectively; lane 5: control TM3 subconfluent culture (not treated); lane 6: a rat heart homogenate used as a positive control for $\mathrm{Cx} 43$. (A) Each lane of the gel was loaded with $100 \mu \mathrm{g}$ total protein before transfer to nitrocellulose. The histogram represents relative densitometry values for $\mathrm{Cx} 43$ labeling, taking the rat heart homogenate as control $(n=3)$. Expression of $\mathrm{Cx} 43$ was not altered by any of the treatments. (B) Relative expression of $\mathrm{Cx} 43 \mathrm{mRNA}$ in subconfluent TM3 Leydig cells, obtained by amplified Cx43 and GAPDH RT-PCR products. The histogram represents the mean \pm S.E.M. values for the ratio between the $\mathrm{Cx} 43$ and GAPDH bands $(n=3)$. The insert shows the agarose gel of a semi-quantitative RT-PCR experiment. RT(-), negative control, performed with $500 \mu \mathrm{g}$ total RNA derived from subconfluent cells in the absence of reverse transcriptase. *Expression of mRNA in rat heart tissue was significantly different from treated and un-treated subconfluent TM3 cells $(P<0 \cdot 05)$. There were no significant differences between all groups of TM3 cells.

The results reported here for $\mathrm{db}$-cAMP are the opposite of what has been found in the majority of other cell types, in which cAMP enhances coupling in spite of the fact that it decreases single channel conductance (Kwak et al. 1995, Moreno et al. 1994). Nonetheless, Sacai et al. (1992) and Cole \& Garfield (1986) reported cAMP-dependent reduction of coupling in myometrial cells and argued that their results were dependent on the stage of maturation of the cell. In addition, in immature rat prefrontal cortex, both cAMP and $\beta$-adrenoceptor activation reduced gap junctional coupling, as demonstrated by a decline in transfer of dye between cells (Rorig et al. 1995).

In contrast, our results with TPA are in agreement with most of those reported in the literature, in which a reduction in junctional conductance has been clearly seen in preparations in which $\mathrm{Cx} 43$ seems to be the main gap junction forming protein (Yada et al. 1985, De Mello 1991, Giaume et al. 1991, Spray et al. 1991). Nonetheless, exceptions have been observed: an increase in coupling after treatment with TPA has been reported in Sertoli cells (Grassi et al. 1986) and in corpus cavernosum smooth muscle cells (Moreno et al. 1993).

It should be pointed out that the data obtained with dye coupling, western blot, immunofluorescence and semiquantitative RT-PCR in the TM3 cells were consistent. Immunofluorescence showed that the TM3 cells displayed Cx43 reactivity localized to the appositional membranes when in pairs or in low confluence, compatible with the high degree of dye coupling measured under these
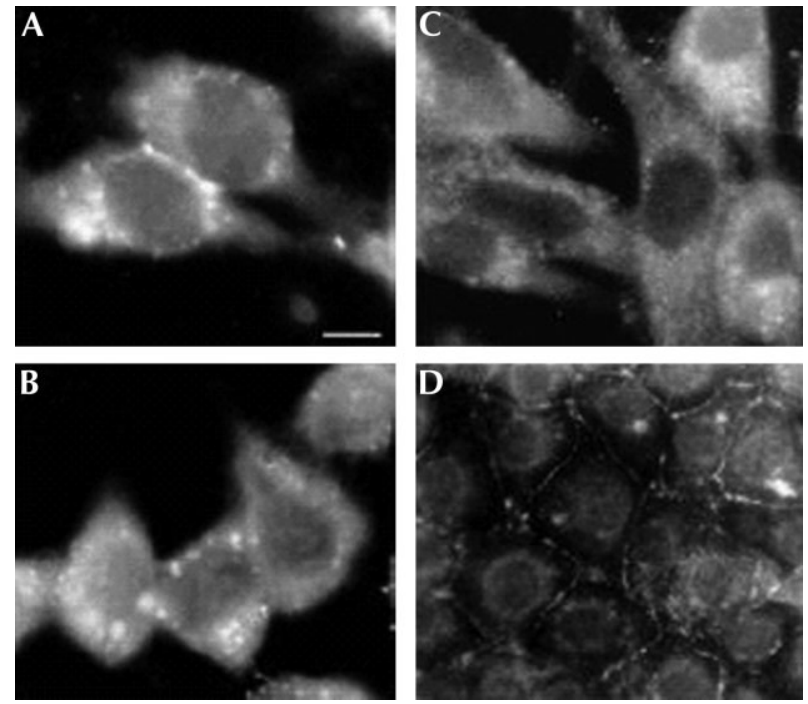

Figure 7 Indirect immunofluorescence for Cx43. (A) Cells forming pairs showed immunoreactivity mainly localized to the appositional membranes, where the gap junction plaques are localized. (B) Treatment of cells in low confluence with $500 \mu \mathrm{M}$ $\mathrm{db}$-cAMP displaced the immunoreactivity from the appositional membranes and dispersed it in the cytoplasm.

(C) Immunoreactivity of cells in low confluence treated with $50 \mathrm{nM}$ TPA. Labeling was diffuse in the cytoplasm, but there was no appositional membrane labeling. (D) Intense membrane labeling in high-confluence cultures treated with $1 \mathrm{mM}$ staurosporin for $1 \mathrm{~h}$. Calibration bar represents $5 \mu \mathrm{m}$ for (A), (B) and (C), and $10 \mu \mathrm{m}$ for (D). 


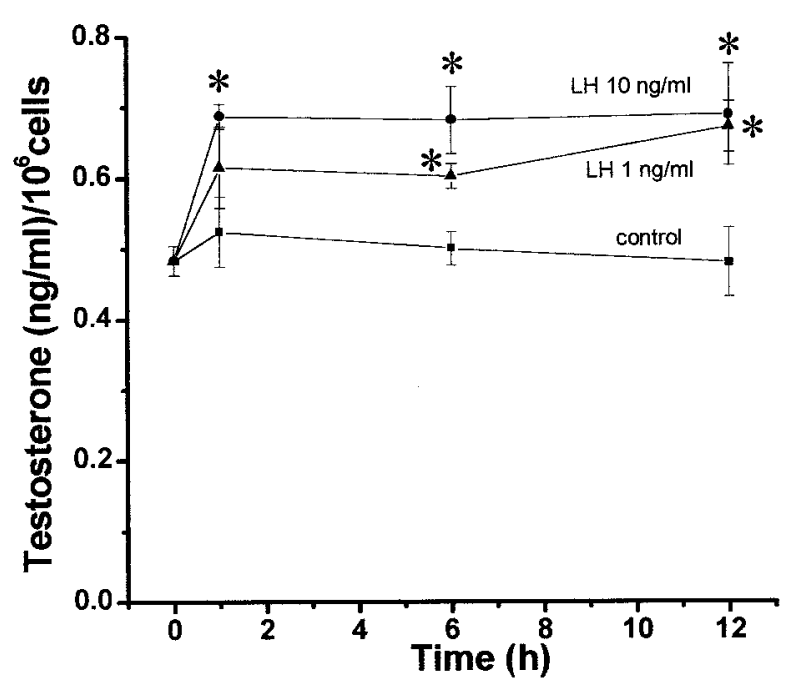

Figure 8 LH-induced testosterone secretion in TM3 Leydig cells. Cells were incubated in the absence of $\mathrm{LH}$ (control) and in the presence of $1 \mathrm{ng} / \mathrm{ml}$ or $10 \mathrm{ng} / \mathrm{ml}$ of the hormone. Values are means \pm S.E.M. $(n=5)$. * Statistically different from control (Student's non-paired $t$-test, $P<0 \cdot 05)$.

conditions. In contrast, confluent cultures not only showed poor dye coupling, but also displayed immunoreactivity to Cx43 localized in the cytoplasm, and not in appositional membranes. Accordingly, western blots and the semiquantitative RT-PCR of confluent cultures showed a lower expression of $\mathrm{Cx} 43$ protein and mRNA respectively, when compared with subconfluent cultures. However, Cx43 mRNA and Cx43 protein concentrations differed by approximately twofold, whereas the percentage of coupling varied by almost 30-fold when we compared subconfluent and confluent cultures, suggesting that other connexins may form gap junction channels between TM3 cells, or that the localization of $\mathrm{Cx} 43$ at membrane appositional areas is the relevant variable.

Granot \& Dekkel (1994) and You et al. (2000) have reported that the expression of gap junctions between rat ovarian cells and between rat Leydig cells respectively can be modulated by PKA and LH - known to induce an increase in the intracellular concentration of cAMP (Duffau et al.1980, Rüegg \& Burgess 1989). Both groups showed that LH induced a significant decrease in $\mathrm{Cx} 43$ mRNA levels after incubation for $24 \mathrm{~h}$, and in the ovarian cells staurosporin blocked these effects.

Many authors have shown that secretion is accompanied by uncoupling in endocrine and exocrine organs. You et al. (2000) have directly measured the production of testosterone and levels of $\mathrm{Cx} 43 \mathrm{mRNA}$ during stimulation of rat Leydig cells by human chorionic gonadotrophin (hCG), both in culture and in vivo. As expected, hCG treatment led to an increase in testosterone formation and a decrease in Cx43 mRNA levels - an effect that was also mimicked by cAMP. These results are consistent with

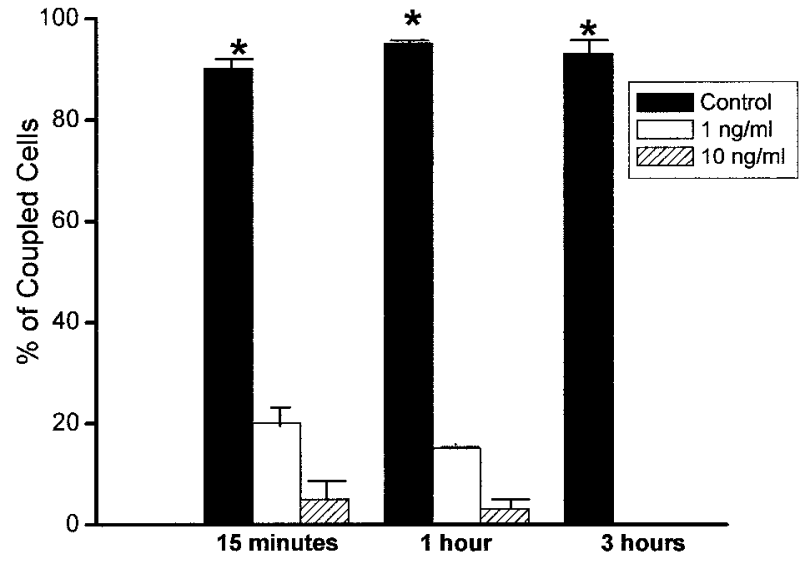

Figure 9 Junctional coupling in TM3 Leydig cells was decreased by $\mathrm{LH}$. Treatment of the cells with $1 \mathrm{ng} / \mathrm{ml}$ and $10 \mathrm{ng} / \mathrm{ml} \mathrm{LH}$ decreased the degree of coupling in subconfluent cultures exposed to the hormone for $15 \mathrm{~min}, 1 \mathrm{~h}$ and $3 \mathrm{~h}$ compared with control (no drug added). The number of cells injected in each condition was 90. *The degree of coupling in the non-treated cells was significantly different from that in treated cells $(P<0 \cdot 05)$.

experiments in which we found that $\mathrm{LH}$ at concentrations ranging from 1 to $10 \mathrm{ng} / \mathrm{ml}$ induced a marked uncoupling of the TM3 cells and a sustained increase in production of testosterone by the TM3 cells. Taken together, these data imply that gap junction mediated intercellular communication may have an important role in modulating hormone production in Leydig cells.

\section{Acknowledgements}

We thank Ms Sonia A Zanon and Mr José Fernando Aguiar for excellent technical assistance. We acknowledge Programa Nacional de Excelência (PRONEX), Conselho Nacional de Desenvolvimento Científico e Tecnológico (CNPq), Fundação de Amparo a Pesquisa do Estado do Rio de Janeiro (FAPERJ), Fundação de Amparo a Pesquisa do Estado de São Paulo (FAPESP), Financiadora de Estudos e Projetos (FINEP), Fundação Universitária José Bonifácio (FUJB) and Surcolombian University, for financial support.

\section{References}

Bennett MVL, Barrio LC, Bargiello TA, Spray DC, Hertzberg E \& Sáez JC 1991 Gap junctions: new tools, new answers, new questions. Neuron 6 305-320.

Berridge M 1984 Inositol triphosphate and diacylglycerol as second messengers. Biochemical Journal 240 345-360.

Bradford MM 1976 Rapid and sensitive method for the quantitation of microgram quantities of protein utilizing the principle of protein-dye binding. Analytical Biochemistry 72 248-254.

Cole WC \& Garfield RE 1986 Evidence for physiological regulation of myometrial junction permeability. American Journal of Physiology 251 C422-C420. 
Cristancho JM, Campos de Carvalho AC \& Varanda WA 2000 Short term regulation of cell-cell communication in TM3 Leydig cells - a perforated patch study. Biochimica et Biophysica Acta 1496 325-332.

De Mello W 1991 Effect of vasopressin and protein kinase c inhibitors on junctional conductance in isolated heart cell pairs. Cell Biology International 15 467-478.

Dermietzel R, Leibstein A, Frixen V, Janssen-Timmen V, Traub O \& Willecke K 1991 Gap junctions in several systems share antigenic determinants with liver gap junctions. EMBO Journal 3 2261-2270.

Duffau ML, Baukal AJ \& Catt KJ 1980 Hormone-induced guanyl nucleotide binding and activation of adenylate cyclase in the Leydig cell. PNAS 77 5837-5841.

Giaume C, Fromaget C, El Aoumari A, Cordier J, Glowinsky J \& Gross D 1991 Gap junction in cultured astrocytes: single-channel currents and characterization of channel forming protein. Neuron 6 133-143.

Granot I \& Dekel N 1994 Phosphorylation and expression of connexin-43 ovarian gap junction protein are regulated by luteinizing hormone. Journal of Biological Chemistry 269 30502-30509.

Grassi F, Monaco L, Fratamico G, Dolci S, Ianni E, Conti M, Eubesi F \& Stefanini M 1986 Putative second messengers affect cell coupling in the seminiferous tubules. Cell Biology International Reports 10 631-639.

Haefliger JA, Bruzzone BR, Jenkins NA, Gilbert DJ, Copland NG \& Paul LD 1992 Four novel members of the connexin family of gap junctions proteins. Journal of Biological Chemistry 267 2057-2064.

Hünster PN \& Weingant R 1993 Effects of phorbol ester on gap junctions of neonatal rat heart cells. Pflügers Archiv European Journal of Physiology 423 181-188.

Kadle R, Zhang JT \& Nicholson BJ 1991 Tissue specific distribution of differentially phosphorylated forms of connexin 43. Molecular and Cellular Biology 11 363-369.

Kwak BR, Van Veen TAB, Analbers LJS \& Jongsma HJ 1995 TPA increases conductance but decreases permeability in neonatal rat cardiomyocyte gap junction channels. Experimental Cell Research 220 456-463.

Lampe PD 1994 Analyzing phorbol esters on gap junctional communication: a dramatic inhibition of assembly. Journal of Cell Biology 127 1895-1900.

Moreno AP, Campos de Carvalho AC, Christ G, Melman A \& Spray DC 1993 Gap junctions between human corpus cavernosum smooth muscle cells: gating properties and unitary conductance. American Journal of Physiology 264 C80-C92.

Moreno AP, Sáez JC, Fishman GI \& Spray DC 1994 Human connexin 43 gap junction channels. Regulation of unitary conductances by phosphorylation. Circulation Research $\mathbf{7 4}$ $1050-1057$.
Oh SY, Grupen CG \& Murray AW 1991 Phorbol ester induces phosphorylation and down regulation of connexin 43 in WB cells. Biochimica et Biophysica Acta 1094 243-245.

Pérez-Armendariz EM, Romano MC, Luna J, Miranda C, Bennett MVL \& Moreno AP 1994 Characterization of gap junctions between pairs of Leydig cells from mouse testis. American Journal of Physiology 267 C570-C580.

Pérez-Armendariz EM, Luna J, Miranda C, Talavera D \& Romano MC 1996 Luteinizing and human chorionic gonadotropin hormones increase intercellular communication and gap junctions in cultured mouse Leydig cells. Endocrine 4 141-150.

Risley MS 2000 Connexin gene expression in seminiferous tubules of the Sprague-Dawley Rat. Biology of Reproduction 62 748-754.

Risley MS, Tan IP, Roy C \& Sáez JC 1992 Cell-cell stage dependent distribution of connexin gap junctions in testes. Journal of Cell Science 103 81-96.

Rorig B, Klausa G \& Sutor B 1995 Dye coupling between pyramidal neurons in developing rat prefrontal and frontal-cortex is reduced by protein-kinase-A activation and dopamine. Journal of Neuroscience $157386-7400$.

Rüegg UT \& Burgess GM 1989 Staurosporin, K-252 and UCN-01: potent but nonspecific inhibitors of protein kinases. Trends in Pharmacological Sciences 10 218-220.

Sacai N, Blennerhasset MG \& Garfield RE 1992 Intracellular cyclic AMP concentration modulates gap junctions permeability in parturient rat myometrium. Canadian Journal of Physiology and Pharmacology $70358-364$.

Skinner MK 1982 Cell-cell interactions in the testis. Annals of the New York Academy of Sciences 513 158-171.

Spray DC, Moreno AP, Kessler JA \& Dermietzel R 1991 Characterization of gap junctions between cultured leptomeningeal cells. Cells Brain Research 568 1-14.

Srivinas M, Costa M, Gao Y, Fort A, Fishman GI \& Spray DC 1999 Voltage dependence of macroscopic and unitary currents of gap junction channels formed by mouse connexin 50 expressed in rat neuroblastoma cells. Journal of Physiology 517 673-689.

Varanda WA \& Campos de Carvalho AC 1994 Intercellular communication between mouse Leydig cells. American Journal of Physiology 267 C563-C569.

Xie H-Q \& Hu VW 1992 Intercellular communication through gap junctions is reduced in senescent cells. Biophysical Journal 62 45-47.

Yada T, Rose B \& Loewenstein WR 1985 Diacylglycerol down regulates junctional permeability. TMB- 8 blocks this effect. Journal of Membrane Biology 88 217-232.

You S, Li W \& Lin T 2000 Expression and regulation of connexin 43 in rat Leydig cells. Journal of Endocrinology 166 447-453.

Received in final form 29 January 2003

Accepted 4 February 2003 